\title{
Muros poéticos: La práctica artística como una herramienta de transformación social y cultural en el contexto urbano
}

\author{
Poetic walls: Artistic Practice as a Tool for Social al Cultural \\ Transformation in the urban context
}

\author{
Eva Figueras Ferrer \\ Universidad de Barcelona (España) \\ efigueras@ub.edu
}

Recibido 30/07/2020 Revisado 10/11/2020

Aceptado 17/11/2020 Publicado 30/11/2020

\section{Resumen:}

Para muchos artistas urbanos nacidos en la segunda mitad del siglo XX, la calle es el marco y el soporte de sus propuestas creativas. A través de sus mensajes poéticos la reivindican como espacio para el arte y se convierten en constructores de ambientes y de formas de vida integral, ya que conciben el espacio urbano como la suma de espacio físico y psíquico con el que interactúa el peatón generando un proceso creativo.

Algunas de las intervenciones urbanas de naturaleza participativa se proyectan y ejecutan con una clara aportación social y educativa. El objetivo de este artículo es presentar distintos proyectos urbanos colaborativos de creación artística que inviten a cuestionar aspectos de la sociedad y promover, por lo tanto, un arte y una sensibilización educativa inclusiva, que aporten valores igualitarios que permitan afrontar retos como la conciencia de la ecología, el hambre, la violencia machista y, por supuesto, cambiar actitudes y comportamientos.

\section{Sugerencias para citar este artículo,}

Figueras Ferrer, Eva (2020). Muros poéticos: La práctica artística como una herramienta de transformación social y cultural en el contexto urbano. Tercio Creciente (Monográfico extraordinario III), págs. 113-128, https://dx.doi.org/10.17561/rtc.extra3.5696

FIGUERAS FERRER, EVA (2020) Muros poéticos: La práctica artística como una herramienta de transformación social y cultural en el contexto urbano. Tercio Creciente (Monográfico extraordinario III), noviembre 2020, pp. 113-128, https://dx.doi.org/10.17561/rtc.extra3.5696 


\section{Abstract:}

For many urban artists born in the second half of the 20th century, the street is the framework and the support for their creative proposals. Through their poetic messages they claim it as a space for art and become builders of environments and forms of integral life, since they conceive urban space as the sum of physical and mental space with which the pedestrian interacts, generating a process creative.

Some of the urban interventions of a participatory nature are planned and executed with a clear social and educational contribution. The objective of this article is to present different collaborative urban projects of artistic creation that invite to question aspects of society and promote, therefore, an art and an inclusive educational awareness, which provide egalitarian values that allow facing challenges such as awareness of the ecology, hunger, sexist violence and, of course, changing attitudes and behaviours.

\section{Palabras Clave: Poesía urbana, prácticas artísticas colaborativas, pintura mural, educación inclusiva}

Key words: Urban poetry, collaborative artistic practices, mural painting, inclusive education

Sugerencias para citar este artículo,

Figueras Ferrer, Eva (2020). Muros poéticos: La práctica artística como una herramienta de transformación social y cultural en el contexto urbano. Tercio Creciente (Monográfico extraordinario III), págs. 113-128, https://dx.doi.org/10.17561/rtc.extra3.5696

FIGUERAS FERRER, EVA (2020) Muros poéticos: La práctica artística como una herramienta de transformación social y cultural en el contexto urbano. Tercio Creciente (Monográfico extraordinario III), noviembre 2020, pp. 113-128, https://dx.doi.org/10.17561/rtc.extra3.5696 


\section{Introducción}

El espacio público como lugar de creación, interacción y de cohesión social es un tema reivindicado y analizado por varios autores en estas últimas décadas (Bassani, 2017; Furegatti, 2017; López \& Morgado, 2017; Martínez, 2017, entre otros), especialmente a partir del impacto de la revolución digital que ha conllevado la expansión del arte urbano a nivel mundial gracias a la Internet. Calles virtuales mundiales que llegan a cualquier lugar del planeta, donde espacio y tiempo adquieren otra dimensión: el "arte" queda legitimado por canales no oficiales y se caracteriza por su expansión ilimitada, así como por la participación ciudadana, ya sea en el transcurso de producción -arte participativo, colaborativo o colectivo (Crespo, 2020)- como de difusión. Evidentemente, los avances tecnológicos permiten una democratización del arte impensable otrora:

La inmediatez de las redes de comunicación, democratiza los procesos de producción y circulación de imágenes, y desestabiliza las viejas jerarquías de Estética. Al mismo tiempo, las nuevas tecnologías de procesamiento de imágenes también han contribuido a la expansión de una cultura visual en la que la producción y la circulación instantánea de las imágenes se ha convertido en una parte discreta de nuestras rutinas cotidianas y que es, en parte, responsable de dar forma a la experiencia visual de la calle contemporánea. (Figueras \& Rosado, 2019 p. 691)

Actualmente, en la calle, el espacio físico y la imagen visual convergen en múltiples niveles. A nivel manifiesto, las imágenes complementan el espacio a medida que intervienen y recrean fachadas urbanas y dan forma al aspecto visual de las calles. Según Christoph Lindner y Miriam Meissner (2018), la experiencia urbana del siglo XXI está enormemente influenciada por la proliferación de carteles, carteleras, anuncios, pegatinas y grafiti en y alrededor de las calles. Estas imágenes, ya sean grandes o pequeñas, detalladas o esbozadas, impresas o en pantallas, provocan respuestas emocionales que son cruciales para la expansión de las políticas urbanas dominantes, como son la creatividad y la gentrificación, y las respuestas contra hegemónicas asociadas. Lindner y Meissner prestan especial atención al papel que juegan los "imaginarios urbanos" en la conformación del futuro de las sociedades urbanas y los ambientes construidos. De acuerdo con estos postulados nos preguntamos ¿Cuál es la función de la educación en general y, especialmente, la educación artística, formal y no formal, en la construcción social de los imaginarios urbanos?

Para dar respuesta a esta pregunta examinaremos algunas intervenciones en las ciudades que se proyectan y ejecutan con una clara intención social y educativa, especialmente en los colectivos vulnerables de la sociedad. Nos detendremos a analizar la importancia de la educación artística que, por su propia naturaleza, es una herramienta de empoderamiento social y cultural aplicable a diferentes entornos educativos y que puede beneficiar de múltiples maneras (salud, bienestar, calidad de vida...) a todos los colectivos sociales. 
La creación artística permite cuestionar aspectos de la sociedad y promover, por lo tanto, un arte y una sensibilización educativa inclusiva, que aporten valores igualitarios que permitan afrontar retos como la conciencia de la ecología, el hambre, la violencia machista y, por supuesto, cambiar actitudes y comportamientos.

\section{Entre muros: El escenario creativo}

Los muros, las fachadas de los edificios o las vallas exteriores del paisaje urbano constituyen un espacio susceptible de ser intervenido: devienen una página en blanco temporalmente a disposición de los ciudadanos y se convierten en los lienzos donde re-escribir deseos, proyectar futuros y buscar complicidad a través de la palabra poética, en colaboración con los conciudadanos y los artistas, como acto performático de crecimiento, de momento mágico y belleza compartida. De esta forma, la ciudad expande a nuevos rangos los escenarios del arte, ampliando el campo de significado disponible para la poética experimental. De acuerdo con Lara "la expansión nos habla de multiplicidad creativa, del desbordamiento de los límites y de las disciplinas, ya sea escultura, pintura, dibujo o escritura, entre otras" (Lara, 2017, p.8).

El muro es uno de los principales elementos urbanos que determinan y condicionan la calidad paisajística. Elemento inerte, incorporado e integrado en cualquier paisaje urbano, el muro puede catalogarse a partir de múltiples entradas y categorías: la pared, la tapia, la fachada, la muralla, el tabique... Destacamos la importancia del mismo como elemento configurador del espacio habitable. Diferenciamos el muro limitador de un espacio degradado o el muro emblemático que marca la última tendencia arquitectónica de la ciudad. Ambos muros son un reflejo de la sociedad y entre ellos transitan los ciudadanos.

Desde los primeros grafitis espontáneos, algunas veces perseguidos y judicializados como vandalismo (Figueras y Rosado, 2015), hasta los proyectos creativos urbanos actuales, las intervenciones artísticas en los muros condicionan el paisaje y la estética de la ciudad y, en consecuencia, las vidas de sus habitantes. No es lo mismo transitar por una calle anónima o por una calle en la que una imagen o un poema apela o invita al transeúnte a detenerse, a contemplar y a reflexionar sobre el mensaje que el artista ha dejado. Se entiende la ciudad "como un escenario creativo que invita a establecer dinámicas de relación e intercambios entre los que hacen obra en la calle y los habitantes del espacio público" (Klein, 2018, p.134). 


\section{La poesía: El guion}

La poesía callejera por tradición ha ejercido la función constructora de un diálogo entre la obra y los habitantes de la ciudad. Muchos artistas activistas recurren a ella ya que, como apunta Klein, "estas intervenciones, como sucedió en el Mayo Francés, priorizan la palabra sobre el arte plástico figurativo o abstracto. Buscan ser, a través de una poesía que haga pensar, una herramienta que genere una reflexión social transformadora hacia la construcción de un nuevo espacio público compartido" (2018, p.126). ¿Espacio real y/o espacio virtual? Mensaje poético que si bien tiene una geolocalización concreta puede convertirse en viral en Internet, a sabiendas que la red es la nueva calle virtual actual (Abarca, 2010).

\section{Educación artística: Telón de fondo}

Algunas de las intervenciones urbanas se proyectan y ejecutan con una clara aportación social y educativa, especialmente a los colectivos vulnerables de la sociedad. La creación ayuda a visibilizar y cuestionar aspectos de la sociedad y promover, por lo tanto, un arte y una sensibilización educativa inclusiva, que aporten valores igualitarios que permitan afrontar retos actuales como la conciencia de la ecología, el hambre, la violencia machista y, por supuesto, cambiar actitudes y comportamientos.

Nos detendremos a analizar algunos proyectos destacados por la importancia que ha tenido la vertiente pedagógica y social como telón de fondo de los mismos.

\section{Ciudadanos y artistas: Los actores}

Algunos proyectos creativos urbanos destacan por ser "un arte más militante" (Vallazza, 2013), que promueve a través de sus obras un despertar de la consciencia colectiva, así como una movilización del habitante de la ciudad. Uno de los principales objetivos es, según Klein, provocar, a través de intervenciones artístico-callejeras en el espacio público, "un giro argumental de la ciudad en busca de un cambio y una transformación social colectiva" (Klein, 2018, p. 129).

Participar en la realización de un grafiti o mural colectivo destinado a embellecer su entorno urbano despierta un sentimiento de pertenencia a una comunidad y, en el sentido metafórico, de propiedad. El muro anónimo adquiere otro protagonismo y sus habitantes, ejecutores y espectadores de la obra, lo observan con un orgullo renovado, "su muro". Además del placer estético al contemplarlo, la pintura es el recuerdo y testimonio de la suma del esfuerzo de diferentes individuales para conseguir un objetivo común: el trabajo en equipo, las negociaciones y los pactos conseguidos a través del diálogo asertivo culminan en una acción creativa y lúdica como es la pintura mural. 
Este despertar de la conciencia colectiva a través del arte podemos encontrarlo en proyectos como Crossroads. El Arte como herramienta de cambio del colectivo Boa Mistura, o en Compartiendo Muros. Arte urbano participativo para dar voz al barrio promovido por la Dirección General de Intervención en el Paisaje Urbano y el Patrimonio Cultural de Madrid. También en el proyecto Traspassant Murs (Traspasando Muros), liderado por la Fundación Setba y realizado en el Centro de Justicia Juvenil Can Llupià de Barcelona.

\section{La obra}

\section{Acto I. Crossroads. El Arte como herramienta de cambio}

Crossroads es un proyecto artístico que pretende inspirar a las personas, implicándoles en el proceso de cambio del entorno en el que viven. Según la presentación del proyecto (consultable en http://www.boamistura.com/\#/crossroads) va dirigido a transformar comunidades vulnerables a través de dinámicas pictóricas participativas. "La realización de murales no sólo supone una mejora estética del lugar, sino que cambia la percepción del barrio como un lugar habitable y fortalece las relaciones que los vecinos tienen de su espacio vital". Transcribimos los objetivos citados en su Web site:

- Creación de una obra de Arte en el espacio urbano, respetuosa y coherente con el contexto.

- Dignificar el entorno de la comunidad mejorando su aspecto, convirtiendo el barrio en un lugar mejor.

- Fomentar el trabajo en red, comunicando a los vecinos e implicándoles como parte activa, para que se sientan también autores de la obra.

- Fortalecer el sentimiento de pertenencia y el de comunidad, así como el orgullo por la identidad propia.

- Fomentar el trabajo en equipo y la creatividad.

- Fortalecer los vínculos personales entre los vecinos de la comunidad generando un tejido social más cohesionado.

- Facilitar un acceso a la educación artística por medios prácticos dando a conocer técnicas y herramientas básicas, incluso con la formación de jóvenes artistas locales.

La colaboración es el elemento principal que articula el proyecto. Los vecinos se convierten en coautores de la obra y se sienten capaces y orgullosos de mejorar las condiciones de su entorno, fortaleciendo el sentimiento de comunidad: la participación, el trabajo en red, el sentimiento de comunidad y el empoderamiento son los conceptos claves a cultivar. Las dinámicas participativas propician la interacción, fomentan el diálogo y refuerzan la comunicación entre vecinos. El resultado es una comunidad más cohesionada y resistente. 


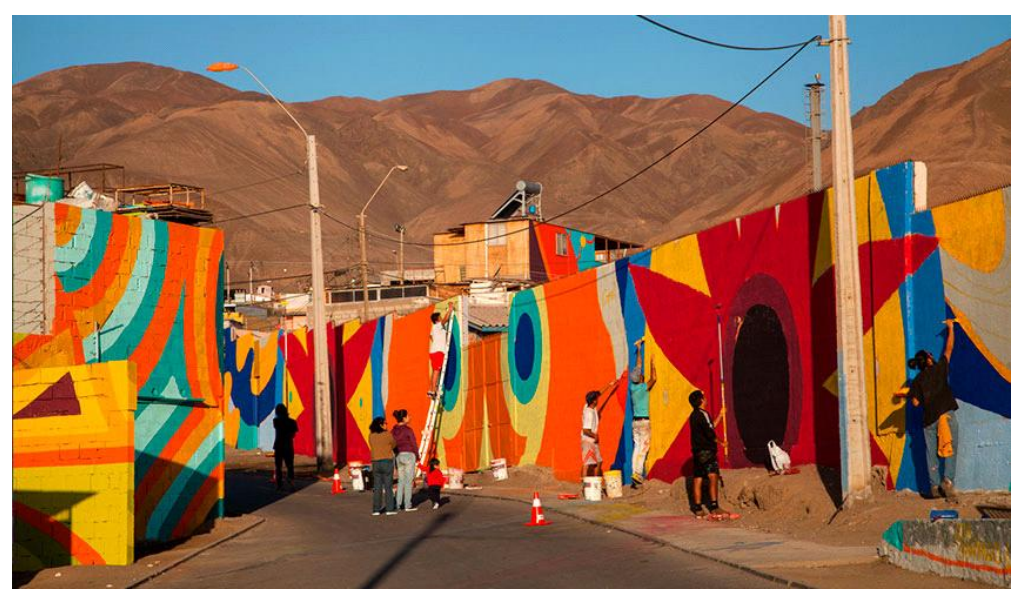

Figura 1. Antofagasta. Proceso de trabajo del proyecto Crossroads en Chile. 2016. (Fotos cedidas por Boa Mistura)

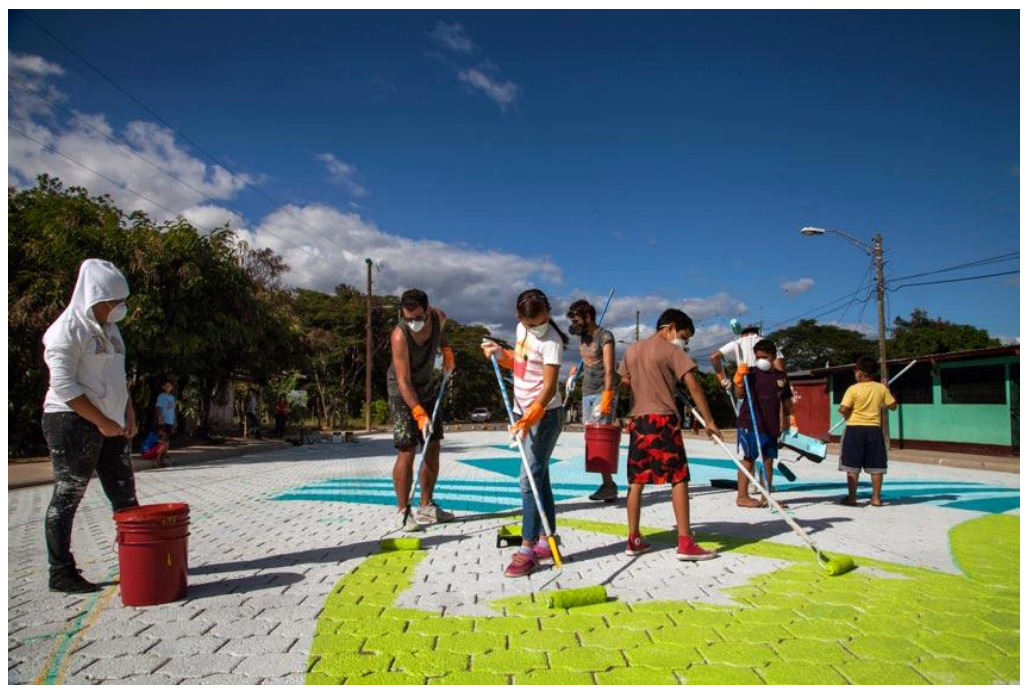

Figura 2. Somoto. Proceso de trabajo del proyecto Crossroads en Nicaragua. 2016. (Fotos cedidas por Boa Mistura)

En los proyectos cooperativos de Boa Mistura la poesía es uno de los vehículos de expresión, entendida no sólo como campo de experimentación con el lenguaje sino también con los materiales, soportes y espacios que ocupa. Las obras rompen los formalismos de la poesía tradicional consistentes en líneas que aparecen impresas en soportes bidimensionales para ser leídas en un orden familiar de izquierda a derecha y de arriba abajo. Su poética desafía estos supuestos utilizando medios materiales propios de la escultura y de la arquitectura, además de la palabra.

Luz nas vielas se realizó en la favela de Vila Brasilândia situada sobre un cerro adyacente a la ciudad de Sâo Paulo, durante el mes de enero de 2012. En el Portfolio online de su sitio web, se narra el proceso de trabajo seguido para llevar a cabo esta intervención artística colaborativa. BELEZA, FIRMEZA, AMOR, DOÇURA y ORGULHO son los conceptos elegidos por el colectivo para las intervenciones en las callejuelas que sirven de elementos 
ISSN: $2340-9096$

https://dx.doi.org/10.17561/rtc.extra3.5696

conectores en el tejido urbano, conocidas como "vielas" y "becos". En 2017 se volvió a la favela para añadir dos obras de anamorfosis, MÁGICA y POESIA. La compleja topografía y el crecimiento urbanístico improvisado han provocado que la favela se estructure desordenadamente. El proyecto busca unificar el espacio mediante el color, de tal manera que se anulan las diferencias entre los distintos materiales que componen las chabolas (Gil, 2012). Al mismo tiempo, las palabras BELLEZA, FIRMEZA, AMOR, DOÇURA y ORGUHLO, con una fuerte carga poética de positividad, unifican un sentimiento de comunidad y de pertinencia a un lugar, su hogar. Al proyectar la obra, Boa Mistura cuenta con la participación de sus habitantes tanto en la toma de decisiones en los procesos de planeación como en la ejecución de los murales. Esta experiencia emotiva queda recogida en el documental Boa Mistura LUZ NAS VIELAS (https://www.youtube.com/watch?v=Ll0bjw3RuII).
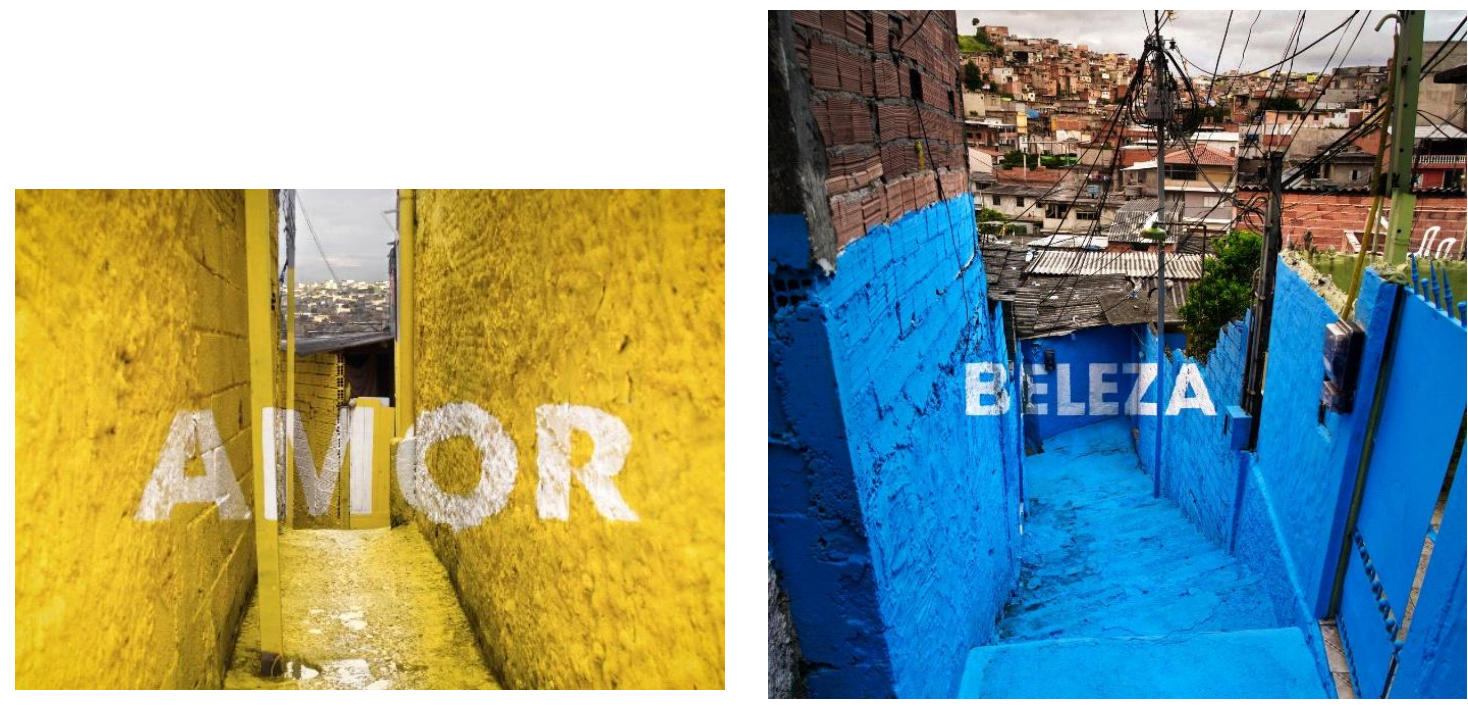

Figura 3, a y b. Amor y Beleza. Luz nas vielas, Sao Paulo (Brasil). 2012. (Foto cedida por Boa Mistura).

La poesía callejera por tradición ha ejercido la función constructora de un diálogo entre la obra y los habitantes de la ciudad. Muchos artistas activistas recurren a ella ya que, como apunta Klein, "priorizan la palabra sobre el arte plástico figurativo o abstracto. Buscan ser, a través de una poesía que haga pensar, una herramienta que genere una reflexión social transformadora hacia la construcción de un nuevo espacio público compartido" (2018, p.126). 


\section{Acto II. Compartiendo Muros}

En 2017, la Dirección General de Intervención en el Paisaje Urbano y el Patrimonio Cultural, como promotora del programa Compartiendo Muros. Arte urbano participativo para dar voz al barrio que gestiona Madrid Destino, pretende dar cabida a la iniciativa ciudadana en la mejora del paisaje urbano a través de intervenciones artísticas murales con la implicación de artistas locales y de los vecinos y vecinas en los 21 distritos de Madrid. Como indica la presentación en la página web del proyecto "dicho programa tiene como objeto que la ciudadanía identifique el espacio público como algo suyo, participe en su embellecimiento y se responsabilice de su conservación y mantenimiento a través de acciones artísticas abiertas a la participación del tejido creativo radicado en el distrito. La expresión artística se concibe desde esta perspectiva como una herramienta de generación de identidad y el programa pretende contribuir a una activación social y cultural de los barrios potenciando el tejido asociativo y vecinal" (http://madridpaisajeurbano.es/paisaje-urbano/compartiendo-muros/)

En una primera fase, estas acciones se desarrollaron en seis distritos de Madrid: Carabanchel, Moncloa-Aravaca, Tetuán, Moratalaz, Puente de Vallecas y Villa de Vallecas, con la colaboración de diferentes colectivos de artistas y creadores especialistas en arte urbano muy reconocidos como son Boa Mistura, Escif, Hyuro, Sr. Mu o Sam3, entre otros.

Comentamos, a modo de ejemplo, las intervenciones Ocarabanchel en Carabanchel y Los claros del bosque en Moncloa-Aravaca.

Ocarabanchel es un "mural y juego de la oca a la vez. Cada casilla representa una viñeta inspirada en las propuestas aportadas por los vecinos durante el taller de recogida de ideas, dirigido por el artista Sr. Mu. El mural es en sí mismo un instrumento de juego, un elemento más del parque, donde además se puede aprender historias del barrio y de sus personajes ilustres. Hay lugares donde las personas pueden integrarse con el diseño, asomándose al muro como en un photocall y dando su rostro a alguna de las figuras que aparecen representadas". 


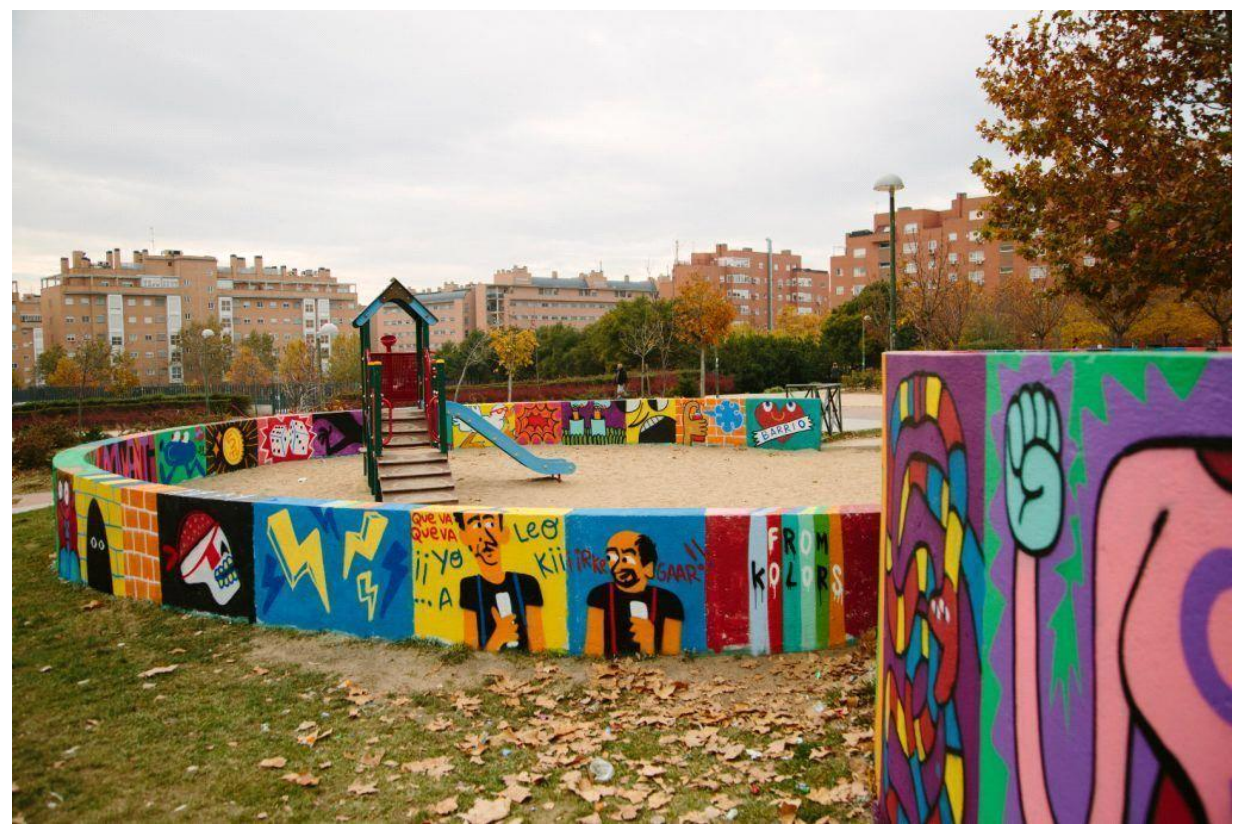

Figura 4. Compartiendo Muros. Ocarabanchel, 2017 (Foto de Web site http://madridpaisajeurbano.es/paisajeurbano/compartiendo-muros/ (C) Ayuntamiento de Madrid 2017. Todos los derechos reservados. 2020)

Los claros del bosque, un dragón con los colores de la vegetación y fauna del parque de Dehesa de la Villa recorre un lugar en el barrio de Valdezarza, una plaza sin identidad y sin nombre en renovación; cuya recuperación llevan mucho tiempo reclamando los vecinos y vecinas. La imagen, que recuerda a la papiroflexia, toma el color rosa de los almendros que florecen en febrero, el verde de la abundante vegetación y los marrones del plumaje de algunas aves como el mochuelo europeo. El cuerpo del dragón hace referencia a un lugar próximo denominado "Parque del Dragón" que forma parte de la memoria del barrio. Con la colaboración de Olor a Pintura, el proyecto quiere rescatar la figura de la escritora María Zambrano al tomar la denominación de su obra Los claros del bosque (1977), en la que utiliza la figura del claro del bosque para expresar parte de su pensamiento filosófico en relación con la poesía. 
Revista de Estudios en Sociedad, Artes y Gestión Cultural
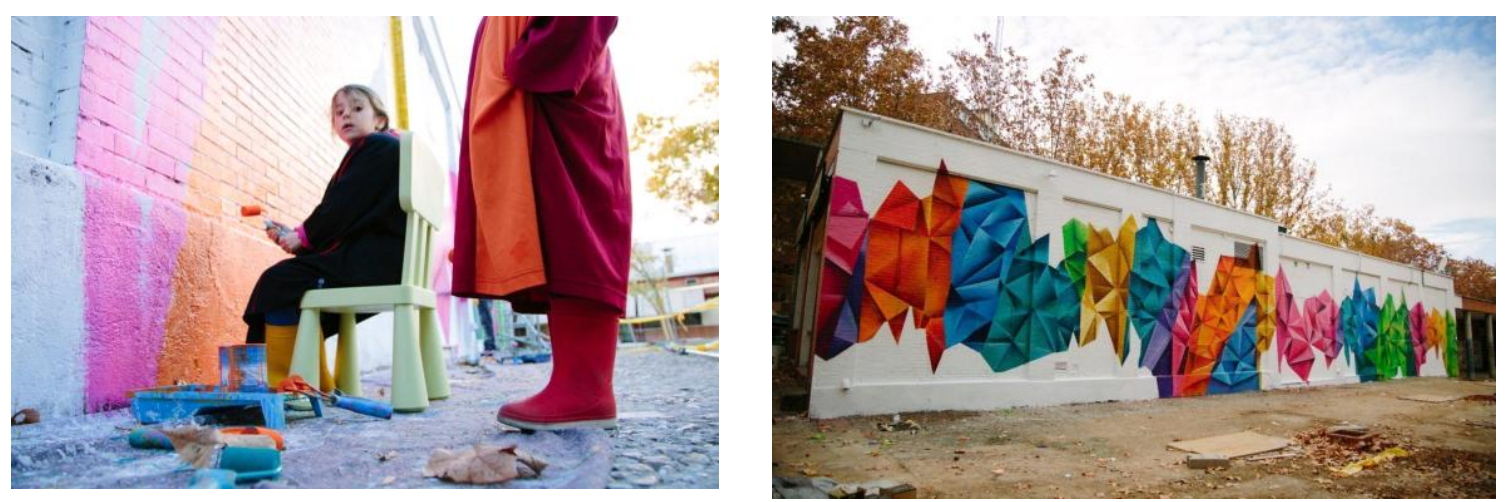

Figura 5, a y b. Compartiendo Muros Los claros del bosque, 2017. (Fotos de Web site http://madridpaisajeurbano.es/paisaje-urbano/compartiendo-muros/ (c) Ayuntamiento de Madrid 2017. Todos los derechos reservados. 2020)

\section{Acto III: Transpassant Murs (Traspasando Muros)}

En primavera de 2018 se inicia el proyecto de pintura mural Traspasando muros, organizado por la Fundación Setba -entidad privada sin ánimo de lucro constituida en 2009 y que centra su actividad a construir espacios de inclusión social a través de la cultura- y con el apoyo del Departamento de Justicia de la Generalitat de Catalunya. El proyecto consiste en una acción participativa bajo la dirección del artista Marcel-lí Antúnez con jóvenes en riesgo de exclusión social. En colaboración con los jóvenes internos se pinta el muro interior del Centro de Justicia Juvenil Can Llupià de Barcelona.

En su segunda edición, en marzo de 2019, la voluntad es que el proyecto salga fuera, en forma de exposición bajo el nombre de Parapupapià. Traspasando muros. Parapupapià se inspira en las fases de desarrollo de una mariposa, desde que es una crisálida (pupa) hasta que se forma completamente, vuela y puede salir al exterior. El trabajo, de continuidad sobre el segundo muro de Can Llupià, se realiza a lo largo de cuatro semanas y participan unos sesenta jóvenes convertidos en artistas entusiastas y comprometidos con su labor. Insectos y pájaros, pintados de múltiples colores sobre el muro, son el motivo conductor para reflexionar sobre temáticas relacionadas con la familia, la cultura, el mundo de las drogas, etc. 


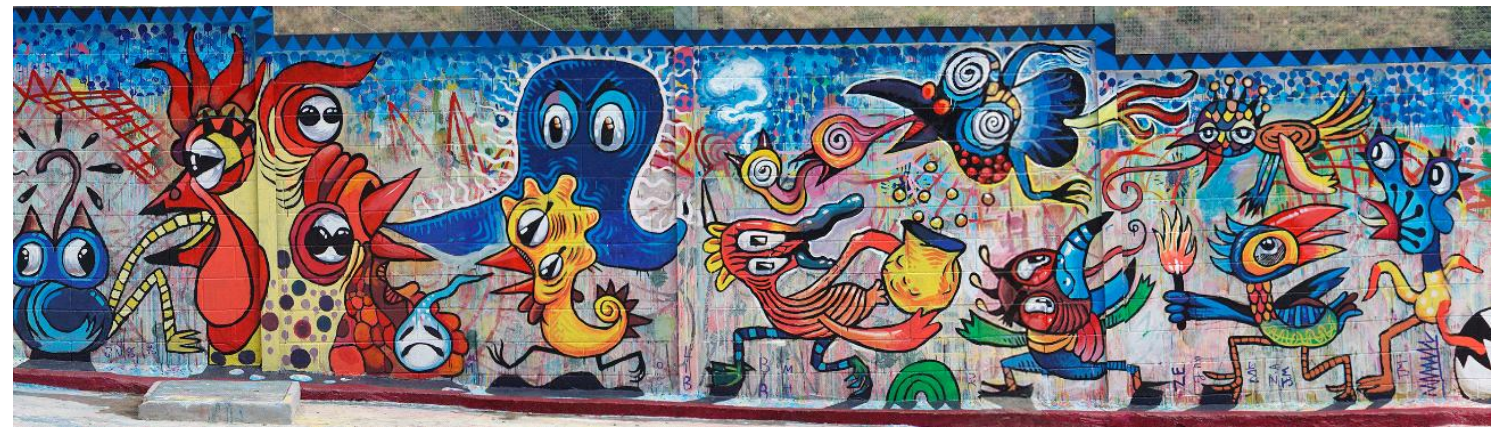

Figura 5. Parapupapià. Traspasando muros, detalle de una parte del mural. (Foto de Carles Rodríguez, cedida por la Fundación Setba)
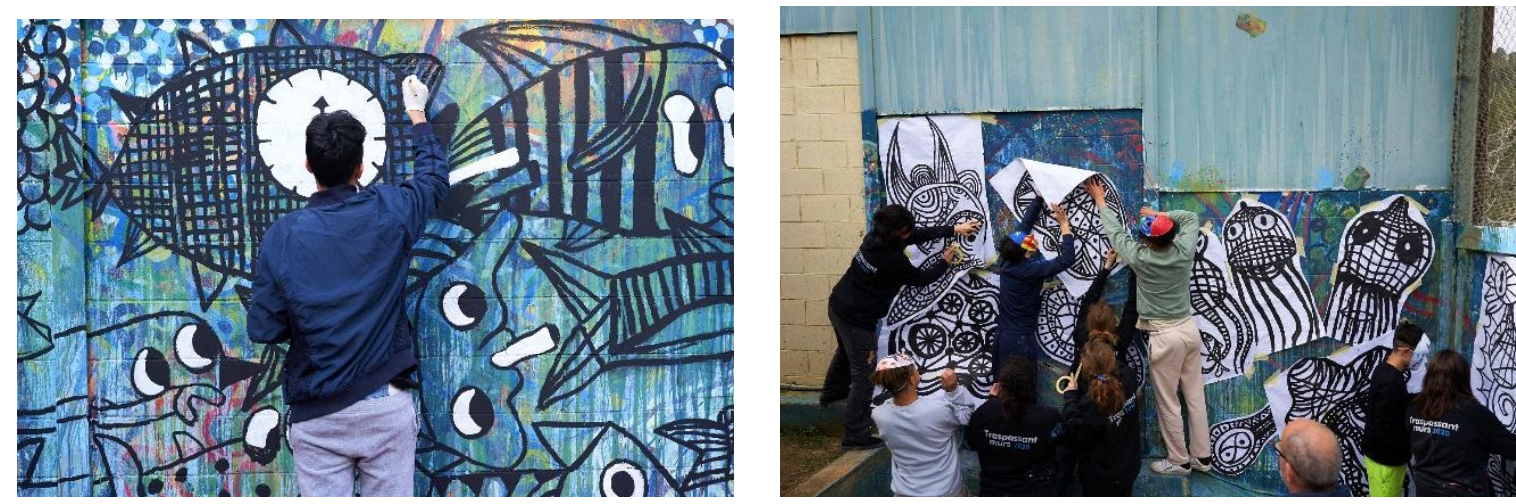

Figuras 6 (a) y 6(b). Parapupapià. Traspasando muros, detalle del proceso de realización del mural. (Fotos de Sara Sanz, cedidas por la Fundación Setba)

Armand Calderó, secretario de medidas penales, reinserción y atención a la víctima, declara que el "proyecto pretende una transformación a través del arte. Desvelar un interés por el arte es importante, pero darse cuenta que también hacen un trabajo en equipo, que detrás hay valores como la autoestima, la responsabilidad”. Asimismo, Marcel.lí Antúnez comenta que la dificultad de los chicos que pasan por el centro "es muy grande y que la solución tangible o práctica muchas veces es difícil, pero a pesar de ello, la posibilidad de ser una persona creativa e imaginarte tu propio mundo es una salida de las posible".

En definitiva, los objetivos marcados en el proyecto tales como despertar el interés por el arte, aprender a trabajar en grupo, fomentar el empoderamiento y la autoestima, así como calmar la ansiedad, se han cumplido y estamos convencidos que ayudan a lograr la reinserción social de los chicos y chicas participantes. 


\section{A modo de conclusión: Baja el telón}

En la introducción formulábamos la pregunta ¿Cuál es la función de la educación en general y especialmente la educación artística, formal y no formal, en la construcción social de los imaginarios urbanos? Para responderla tenemos que puntualizar, en primer lugar, que todos los ejemplos presentados se han realizado en un contexto "educativo" no formal, en el que entendemos la educación artística como una herramienta de transformación social y cultural que puede beneficiar de múltiples maneras a los ciudadanos. La creatividad es una actividad que conlleva, por una parte, un carácter renovador $\mathrm{y}$ de aprendizaje $\mathrm{y}$, por otra parte, un carácter ético que promueve aportaciones a la esfera humana. La práctica de una actividad creativa colaborativa propicia el diálogo entre los participantes y favorece el desarrollo del pensamiento crítico.

Las intervenciones urbanas referidas en este artículo son modelos de procesos creativos corales, donde el protagonista plural es un elemento clave de empoderamiento del colectivo. Si estas prácticas artísticas se realizan con la colaboración de grupos sociales vulnerables el beneficio es multiplicador ya que desencadena acciones y actitudes tales como: el empoderamiento y orgullo de embellecer su hábitat, despertar el interés por el arte, aprender a trabajar en grupo, fomentar la autoestima, calmar la ansiedad...

De acuerdo con Sergio García, “el objetivo final de un espacio público -más allá de su función- es ser identificado como tal por sus usuarios, alcanzar carácter propio, conseguir hacerse acreedor de su aceptación ciudadana y parte intrínseca de la Ciudad" (García, 2014, p.314). Y la mejor manera de conseguir la identificación y aceptación ciudadana es dar cabida a su participación en la mejora del espacio habitado a través de actuaciones que suponen pequeños desarrollos culturales que se insertan en la realidad específica de cada contexto urbano: esto es, desde la favela y barrios marginales de Latinoamérica, pasando por determinados barrios de Madrid hasta llegar a un Centro de Justicia Juvenil de Barcelona. Con estos proyectos mejoramos no sólo la calidad de los espacios públicos y de la ciudad en sí misma, sino la de sus habitantes. 


\section{Referencias}

Abarca, J. (2010, septiembre). "El papel de los medios en el desarrollo del arte urbano". En: Asociación Aragonesa de Críticos de Arte, 12. Recuperado el 10 de junio de 2020, de http://www.aacadigital.com/contenido.php?idarticulo=372.

Barreri, D. (2020). Crossroads. Boa Mistura. Audiovisual from Spain. Recuperado el 10 de junio de 2020, de: http://www.audiovisualfromspain.com/audiovisual/es/navegacionprincipal/mercados/sunny-side-of-the-doc/lineup/VID2019822851 ES ES.html\#VID2019822851_ES ES

Bassani, Jorge (2017). “Arte colectivo y política en perspectiva urbana”. En: Arte y Ciudad. VIII Jornadas Arte y Ciudad. V Encuentros Internacionales. Universidad Complutense de Madrid.

Boa Mistura. Crossroads. El Arte como herramienta de cambio. Recuperado el 10 de junio de 2020, de http://www.boamistura.com/\#/crossroads

Boa Mistura (13 junio 2012). "LUZ NAS VIELAS". Recuperado el 15 de mayo de 2020, de https://www.youtube.com/watch?v=L10bjw3RuII

Crespo-Martín, Bibiana. (2020). “Acerca de las prácticas artísticas participativas contemporáneas como catalizadoras de la sociabilización". En Historia y comunicación social 25(1), 275-286. http://dx.doi.org/10.5209/hics.69244

Delgado, M. y Malet, D. (2007). El espacio público como ideología. Urbandoc.1, 57-65. $\begin{array}{lllllll}\text { Recuperado el } & 16 & \text { de } & \text { mayo de }\end{array}$ http://www.fepsu.es/docs/urbandocs/URBANDOC1.pdf

Figueras Ferrer, E. y Pilar Rosado Rodrigo (2019). "Poéticas expandidas. La influencia de las nuevas tecnologías digitales en la experiencia urbana del siglo XXI". En: Redes sociales, tecnologías digitales y narrativas interactivas en la sociedad de la información. Javier Sierra Sánchez y José María Lavín (coords.), Mc Graw Hill, p. 689-701. 
Figueras Ferrer, E. y Pilar Rosado Rodrigo (2015). "Street Art en acción: del grafiti artesanal al soporte digital". En: Asociación Nacional de Investigadores en Artes Visuales, II Congreso Internacional de Investigación en Artes Visuales. ANIAV2015. Editorial Universitat Politècnica de València. https://doi.org/10.4995/ANIAV.2015.1307

Font, Marta (10 de abril 2019). Can Llupià promou l'art entre joves interns per millorar-ne la conducta. Betevé- Recuperado el 3 de junio de 2020, de https://www.fundaciosetba.org/traspassant-murs-a-beteve/

Furegatti, Sylvia (2017), "Aspectos de la relación Arte, Naturaleza y Paisaje en la contemporaneidad". En: Arte y Ciudad. VIII Jornadas Arte y Ciudad. V Encuentros Internacionales. Universidad Complutense de Madrid.

García Doménech, Sergio (2014). "Percepción social y estética del espacio público urbano en la sociedad contemporánea". En: Arte, Individuo y Sociedad, 4, 26 (2) 301-316. http://dx.doi.org/10.5209/rev_ARIS.2014.v26.n2.41696

Gil, E. (2012, marzo 16). Luz nas Vielas, intervención urbana de Boa Mistura en São Paulo. Experimenta. Recuperado el 10 de febrero de 2020, de https://www.experimenta.es/noticias/grafica-y-comunicacion/boamisturaluz-nas-vielasmedium-resolution-3430/

Klein, Ricardo (2018) “Ciudades literarias y espacios públicos creativos. Un análisis de poesía callejera en Latinoamérica y Europa". En: Debats, 132 (2) 125-136. http://dx.doi.org/10.28939/iam.debats.132-2.12

Lara, J. (2017). Literatura expandida. Ajuntament de Sant Cugat: Centre d'Art Maristany.

Lindner, Christoph y Miriam Meissner (2019). The Routledge Companion to Urban Imaginaries. London \& New York: Routledge. https://doi.org/10.4324/9781315163956

López Moreno, I. y Borja Morgado Aguirre (2017). "Nuevos lugares para una práctica artística colectiva responsable: el Festival Al Sur del Barrio de El Carmen, Murcia". En: Arte y Ciudad. VIII Jornadas Arte y Ciudad. V Encuentros Internacionales. Universidad Complutense de Madrid. 
ISSN: $2340-9096$

https://dx.doi.org/10.17561/rtc.extra3.5696

Madrid Destino (2017-2020). "Compartiendo Muros. Arte urbano participativo para dar voz al barrio". Recuperado el 13 de junio de 2020 de http://madridpaisajeurbano.es/paisajeurbano/compartiendo-muros/

Martínez Biot, Bárbara (2017). "Prácticas artísticas colaborativas en la ciudad de Valencia". En: Congresos de la Universitat Politècnica de València, III Congreso Internacional de $\begin{array}{lllll}\text { Investigación en } & \text { Artes } & \text { Visuales. } & \text { ANIAV }\end{array}$ http://dx.doi.org/10.4995/ANIAV.2017.5847

Vallazza, E. (2013). "Nuevas tecnologías, arte y activismo político". En: Cuadernos del Centro de Estudios en Diseño y Comunicación, 45, 39-52. 